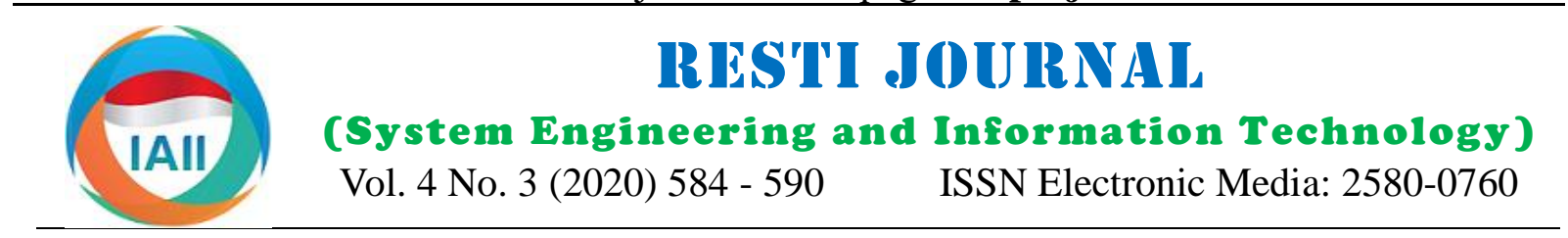

\title{
How Can IoT Applicable to Practice Gross Motor Skill Through Hopscotch Game?
}

\author{
Irvan Naufali Rahmanto ${ }^{1}$, Novian Anggis Suwastika ${ }^{2}$, Rahmat Yasirandi ${ }^{3}$ \\ ${ }^{1,3}$ Informatics, School of Computing, Telkom University \\ ${ }^{2}$ Information Technology, School of Computing, Telkom University \\ 1'irvanrahmanto@student.telkomuniversity.ac.id, ${ }^{2}$ anggis@ telkomuniversity.ac.id, ${ }^{3}$ batanganhitam@telkomuniversity.ac.id
}

\begin{abstract}
Motor development is the result of changes caused by physical growth, muscle strengthening, and the ability to interact with the environment. There are two types of motor development, namely gross motor and fine motor. The best age for a child for motor development is 0 to 8 years. At the age of 4 to 6 years mostly of children's gross motor activities related to balance and coordination. Child's development of gross motor can be achieved by stimulating using games. Hopscotch is type of game that implements balance and coordination skills that support the development of gross motor skills. In Indonesia, children aged 4 years to 6 years have started to enter the Early Childhood Education and Kindergarten level. When the child is at school, parents cannot provide motor stimulation and must wait for the child's motor development reports submitted by the teachers. In this study we implemented system to stimulate the development of gross motor balance and coordination in children aged 4 to 6 years using hopscotch game integrated with Internet of Things (IoT) technology. IoT provides the ability to read, record, and evaluate children's activities and publish their results online for parents to access. This system is evaluated based on the system's functionality and performance parameters. From the test results found that the functionality of the system runs $100 \%$ by the specified function. The system performance test results from the sensor readings are under 1 second and the accuracy of the assessment activity of the first test variation of the foot position in the middle of $68.75 \%$, and the foot position at the edge of $81.25 \%$ with the program delay setting from the node to the IoT platform an average of 1 second.
\end{abstract}

Keywords: Gross Motor Development, Hopscotch Game, Internet of Things (IoT), System Performance.

\section{Introduction}

Development can be interpreted as results of physical changes and maturity that occur in humans, to carry out activities with their experience [1]. Motor development is a learning process that occurs in children to skillfully move limbs [1]. Motor development itself occurs at the age of 0 months to 8 years [2]. Motor development in question includes gross and fine motor development. Gross motor is the ability to move part of the whole body that involves large muscles [3], whereas the fine motor is a movement that is done by involving certain body parts and performed by small muscles [1].

According to the Ministry of Health of the Republic of Indonesia in 2016, child development screening was measured using the Kuisoner Pemeriksaan Pra-Skrining Perkembangan (KPSP) [4]. Screening is an effective way of early detection. Ideally, a child development screening test covers all areas of development including motor development. In practicing gross motor skills such as balance and coordination can be done with the activity of standing one foot, jumping on one foot without holding on for several times [4]. At the age of 4 to 6 years, the majority of gross motor activity in children is related to balance and coordination skills [5]. Play or games as activities related to the child's overall self is to encourage children to practice skills that lead to the child's motor development [1]. One of them with hopscotch or crank. The game of hopscotch was chosen because it can stimulate balance and coordination by practicing the activity of standing on one foot, jumping on one foot without holding on [1]. Then at the age of 4 to 6 years, children have entered the Early Childhood Education and Kindergarten level [5]. Parents who can no longer provide motor stimulation to their children are required to wait for reports from teachers who at school can directly observe related developments [6].

To make observations and assessments automatically, the IoT technology is needed. Because this technology will detect activities that are embedded in objects and eventually be able to interact across networks and connect [7]. With technology that can be applied

Accepted by editor: 18-05-2020 | Final Revision: 06-06-2020 | Online Publication : 20-06-2020 
anywhere and support in improving the learning process be done. Then the next process discusses the test and the knowledge process [8]. So that in this study, scenario of the system built, from functionality and analysis and implementation of the system using the performance perspective. After that, the results of the hopscotch game utilizing IoT technology as a medium test scenarios will be analyzed based on the parameters for assessment and learning. With a device that is built specified, until finally concluding the conclusion stage. and can be used by children in playing hopscotch games according to the instructions jumping one or two feet.

\subsection{Study of Literature}

Will be tested on system functionality, and analysis of

At present applying IoT in the field of education system performance based on parameters read speed and accuracy rate. This is needed for the suitability of the output in terms of speed and accuracy of the sensor, which will send data to Thingspeak as an IoT platform.

\section{Research Method} becomes important to be used in improving learning abilities and knowledge, especially education in children [8]. The learning and education model itself has transformed towards independent and collaborative use of technology [9]. Technology is very influential in all activities that support learning, for example in terms of content involvement [10]. IoT itself is a sub-category of The research method study based on experimental internet technology, which benefits are very broad as method that conducts by experiments or tests of the built students can access learning materials and information system. Then the series of experimental research from anywhere and at any time, it can even be monitored methods consist of Methodology, Literature Study, and by the teacher [10]. With the child's interest in playing, System Design.

\subsection{Methodology} and the aim to stimulate children's development by utilizing IoT technology. Therefore, in playing as a learning medium, development is needed in order to treat Flowchart in Figure 1. Research Method below, show child development with a game system that utilizes IoT the research methodology.

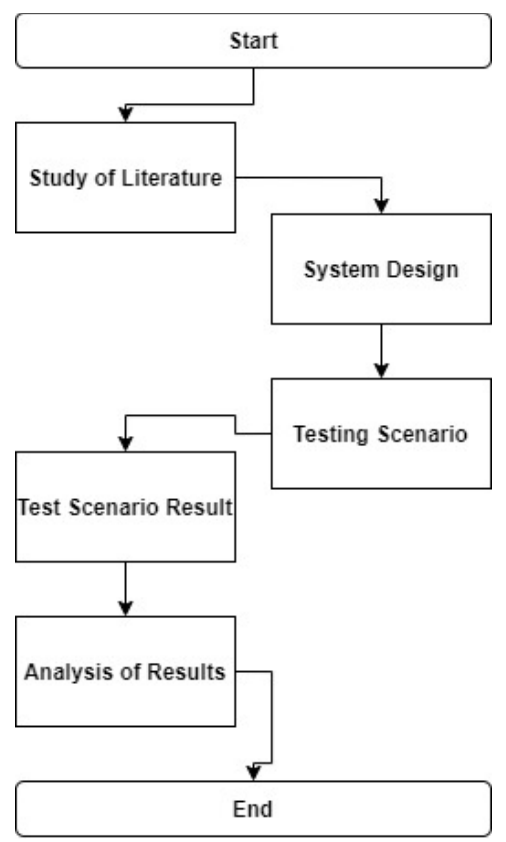

Figure 1. Research Method to make it easier for teachers or parents to monitor their development.

Iyan Nurdiyan Haris in their research, have found a mechanism to improve gross motor balance. In their research, applying the effect of stilts training and Sodor's gobak to the body balance of SDN 1 Subang students [11]. The sample consisted of 30 male students divided into two groups, 15 egrag exercises, and 15 sodor exercises. The research instrument was a stand test stroke with the results of calculations and data analysis that the egrag exercise was obtained t count 2.66, $t$ table 2.05 at the real level ()$=0.05$ with $\mathrm{dk}=28$ then there was a significant influence from the game of stilts. The result of Sodor Grobag Analysis obtained T value of 1.71 while the value of table $=2.05$ at the real level () $=0.05$ with $\mathrm{dk}=28$, this means that there is no significant effect on the Sodor cart.

Wiranti, Dwiana Asih and Diah Ayu Marwati [12] conducted a study of the effectiveness of the crank play in developing gross motor skills of early childhood. The research they did by collecting experimental data with the type of one group pretest and posttest. Analysis of ttest data with the t-test technique. The results obtained prove that the majority of children are in the criteria of Beginning to Develop (MB) when the pretest and the criteria of Very Good Development (BSB) after the posttest.

The research method in Figure 1. Research Method is the stages carried out in the study, it can be interpreted as a sequence of processes from first to end. In the first process the research focuses on the study of literature or Research conducted by Sriwidari et al [13] namely The researching, and referring to previous research, based on Modification of Hopscotch Developing Children's Gross specifically relating to the stimulus of gross motor Motor and Social, with observation data collection children development. Furthermore, after conducting a techniques using a rating scale instrument model, then literature study, system design is carried out in the next testing statistical data with the Mann Whitney test to get process. The system design will discuss what devices are the results that hopscotch affects the gross motor skills used, system communication and implementation will of children and social development with an average 
value and significance level of Asymp sig.tailed 0,000 and less than 0.05 .

Then research conducted by Jorge G'omeza et al [8] with the title "Interaction Systems Based on the Internet of Things as Support for Education" discusses the field of education where the Internet of Things can be used to create more significant learning spaces. A system that allows students to interact with physical objects around them virtually are related to learning. An approaching with experimental validation is applied which results in this model improving student learning outcomes, with utilizing real objects, and linking them as learning media through the internet to facilitate teaching and learning.

Miguel A. Prada et al [14] with the title "Communication with resource-constrained devices through MQTT for control education" is a research that discusses lightweight protocols for communication with devices with limited resources. To evaluate this approach, educational applications focused on DC motor position loop control that built with EjsS, which used MQTT protocol to communicate with the Arduino microcontroller which is implemented with the MS150 modular feedback system.

\subsection{Gross Motor in Hopscotch Games}

Gross motor is the ability to move the body in using large muscles, this movement need more demanding of physical strength and balance. The motor is an action that can cause motion/motor [15], Bambang Sujiono et al argues that the gross motor movements of children are abilities that require coordination in most parts of the child's body. The goal of developing gross motor skills of children, is to introduce gross and fine movements, to practice gross and fine movements by enhancing body skills and a healthy way of life. Because the motor skills of children on 4-5 years old will be more developed in gross motor skills (Hurlock: 1998) [15]. According to Barrow Harold M., and MC Gee, Rosemary (2976: 120) the elements of motor skills consist of strength, speed,
power, agility, balance, flexibility, and coordination power, agility, balance, flexibility, and coordination
[16]. These same elements are explained by Toho Cholik Mutohir and Gusril (2004: 50-51) where coordination is a skill to unite or separate in one complex task simultaneously. While the balance is a person's skill to maintain the body in various positions [16].

Hopscotch or commonly known as the game of cricket learning process [8]. All forms of activities that can be is one of the most famous traditional games to be played carried out using the media strongly support the by children in many countries around the world, implementation of the IoT system. IoT itself is a although there are differences in content from many development of Information \& Communication versions originating from different countries or regions. Technology (ICT) which aims to help the development Generally, the game is played by two or more children, of education [20]. Among the potentials of IoT to according to Keen Achroni (2012: 52) the steps of the improve quality in education are examples - such as in hopscotch game include: (1) the player places the game the fields of mobile learning, smart objects, pawn into the plot, the pawn cannot exceed the box or gamification, and virtual world [21].

plotline, (2) the player jumps from one plot to another

plot, where the other plot uses one same foot, (3) the box

contained in the pawn will not be stepped on by any player. When jumping, children should be able to stand on a box by box without being allowed to shape the outline of the box. Besides, players must also pay to whether there are opponent pawns in one plot. If there is an opponent's pawn, then the box must not be trampled on, this means the player must be able to jump over to the next box [12]. Hopscotch game or crank is an activity that requires gross motor skills, namely jumping on one foot.

\subsection{The Role of IoT in Education}

Conceptually, the Internet of Things (IoT) aims specifically to expand, making use of all the internet connectivity needs that are constantly connected [17]. According to Casegras (Coordination and support for global RFID-related activities and physical and virtual objects through the exploitation of data capture and the ability to communicate with each other [18], [19]. IoT enables control, communication, cooperation with various data, hardware, and internet, through an internet network or called M2M (Machine to machine). Kevin Ashton 2009 defines that the beginning of the IoT is the Internet of Things that has the potential to change the world as the internet might done even better [17]. With the functionality of Protocol (IP) addrect After the exchange of information between objects, the object can work by itself or even order other objects to come to work [4]. Potential applications of IoT are numerous and varied, spreading to almost all areas of the daily life of each individual, other society as a whole [7]. According to the Internet of Strategic Things Research Agenda (SRA) during 2010, ix or more application domains were identified namely mart energy, smart health, smart buildings, smart Education, as activities carried out by humans now have begun to shift to the phenomenon of technology, specifically IoT. To help the process of knowledge, this will result in increased access to learning content supported by technology. Applying education through electronics with the IoT field is the use of this field in the 2.5. System Design 


\subsubsection{Flowchart Diagram}

Figure 2. Flowchart Diagram represents the flowchart on the game system that starts when the play activity is carried out, then the activity is recorded by the sensor until then sent to the IoT platform. In this study, in addition to the process of recording activities, a system that allows us to measure its performance based on the parameters specified.

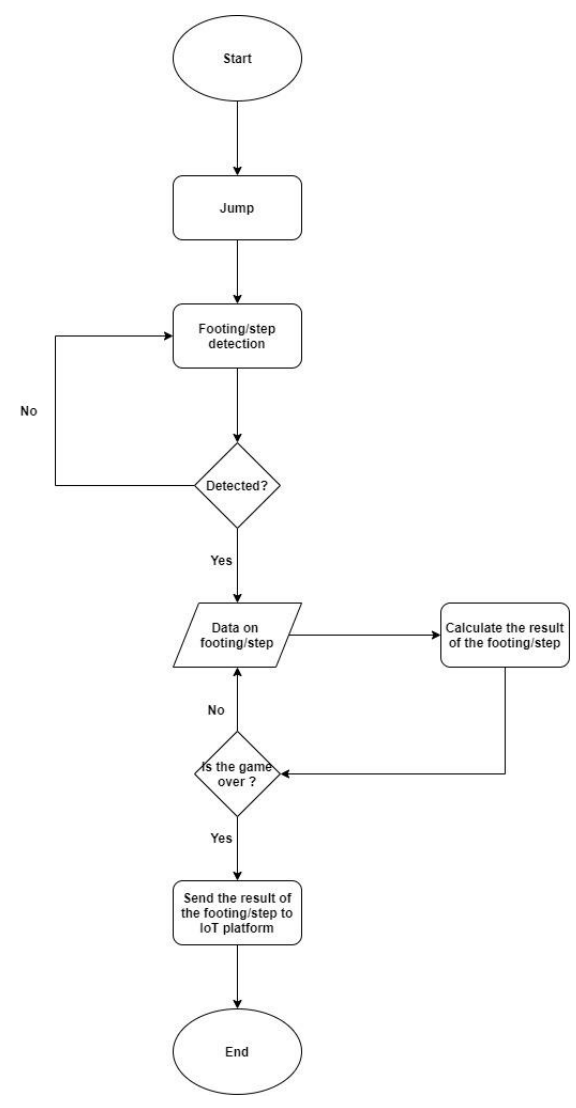

Figure 2. Flowchart Diagram

\subsubsection{System Architecture}

The system architecture of the hopscotch game system can be seen in Figure 3. System Architecture, which represents the architecture of the system being built, by illustrating how the system works on user involvement, games that are applied, devices used and data/information communication until it starts from the beginning to the end until it is sent via the Internet. Some studies related to uploading sensor data to the internet are IoT based environmental monitoring systems using Arduino and thingspeak [22], and thingspeak based sensing and monitoring systems for IoT [23].

First, when the user starts to perform activities or play on the hopscotch game system, each activity carried out such as jumping, stepping will be begin to be recorded, which each step footing is an input that will be processed to the system. Furthermore, if the game is finished, the output on the serial monitor will be sent to the IoT platform using the internet.

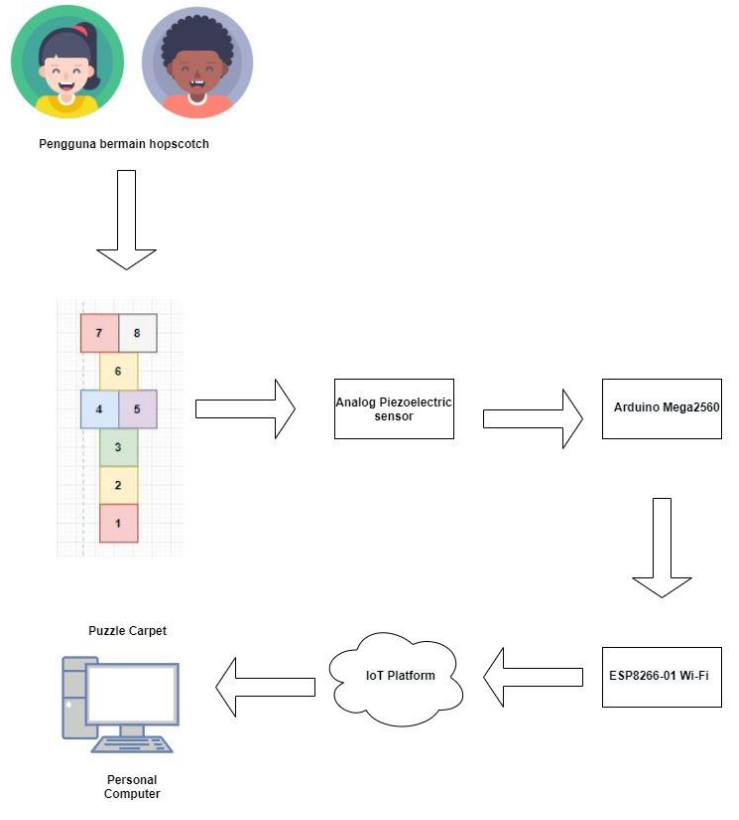

Figure 3. System Architecture

\subsubsection{Tool Representation}

The representation of built device involves several hardware components with device circuit block diagrams, as showed on Figure 4. Tool Representation and Figure 5. Circuit Block Diagram.

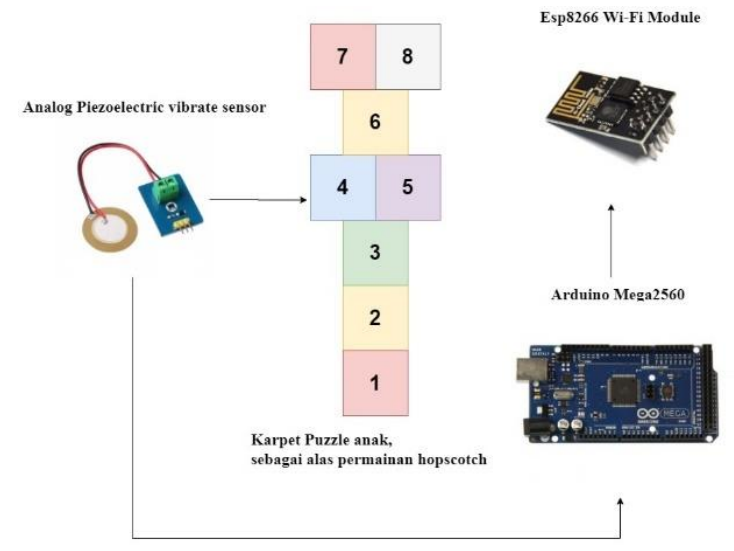

Figure 4. Tool Representation

The tool representation in Figure 4. Tool Representation consists of devices such as a microcontroller, sensor, and Wi-Fi module.

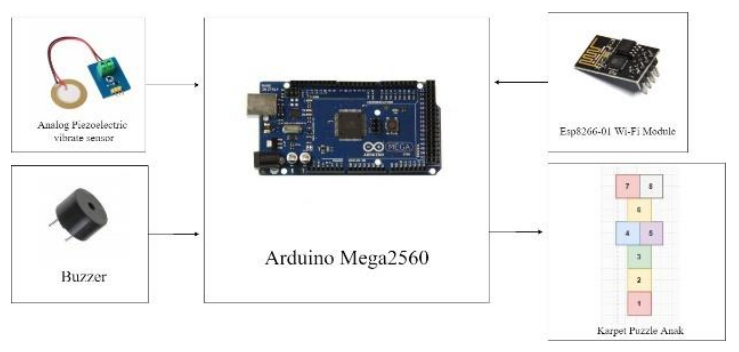

Figure 5. Circuit Block Diagram 
While block diagram in Figure 5. Circuit Block Diagram assessment parameters, means accuracy of assessment in is arrangement of the devices together, the function of the game system device compared with value of manual which is explained in table 1.

Table 1. Tool Functionality

\begin{tabular}{ll}
\hline \multicolumn{1}{c}{ Devices } & \multicolumn{1}{c}{ Information } \\
\hline Arduino Mega2560 & Function as a microcontroller. \\
$\begin{array}{l}\text { Analog } \\
\text { Piezoelectric } \\
\text { ceramic vibrate } \\
\text { sensor }\end{array}$ & Serves to detect footing or footsteps. \\
Esp8266-01 & $\begin{array}{l}\text { Function as a Wi-Fi module to send data } \\
\text { to the internet. }\end{array}$ \\
Karpet puzzle anak & $\begin{array}{l}\text { Functioning as a media base for } \\
\text { hopscotch games. } \\
\text { Serves as a foothold indicator that has } \\
\text { been detected by a piezoelectric ceramic } \\
\text { vibrate sensor. }\end{array}$ \\
\hline
\end{tabular}

\subsubsection{Algorithm}

Then to facilitate understanding in the program, it will be described programming algorithm that used on the sensor for footing detection, as contained below.

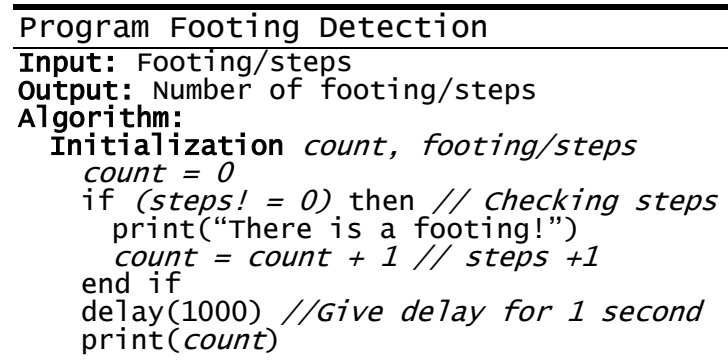

\subsubsection{Testing Scenario}

The testing scenario that will be carried out, is testing system functionality and system performance on the hopscotch game system. The functionality of this device consists of components, namely hardware. The hardware component has a function and role for each test statement described in Table 2.

Table 2. Functionality System

\begin{tabular}{|c|c|c|}
\hline Component & Devices & Information \\
\hline \multirow{3}{*}{ Hardware } & $\begin{array}{l}\text { Arduino } \\
\text { Mega2569 }\end{array}$ & $\begin{array}{l}\text { Testing } \\
\text { microcontroller can } \\
\text { work according to } \\
\text { the program. }\end{array}$ \\
\hline & $\begin{array}{l}\text { Analog } \\
\text { Piezoelectric } \\
\text { sensor }\end{array}$ & $\begin{array}{l}\text { Test the workings of } \\
\text { sensors used to detect } \\
\text { objects, i.e. footing. }\end{array}$ \\
\hline & $\begin{array}{l}\text { Esp } 8266 \mathrm{Wi}-\mathrm{Fi} \\
\text { module }\end{array}$ & $\begin{array}{l}\text { Testing the Wi-Fi } \\
\text { module, whether data } \\
\text { can be sent to the } \\
\text { internet. }\end{array}$ \\
\hline
\end{tabular}

Furthermore, the system performance will use speed read parameter, which means how long the device process when receiving instructions or commands and processing it into an input. Then the accuracy of test.

\section{Result and Discussion}

Tests carried out on microcontroller devices, vibrate sensors and wi-fi modules. The discussion in this section will be divided into a discussion of system functionality and system performance.

\subsection{System Functionality Test Result}

\subsubsection{Arduino Mega2560}

Arduino Mega2560, which acts as a microcontroller will be main control of system. In figure 6. Arduino Mega2560 Testing the Arduino red lights successfully turn on after connected to the laptop / pc via a USB cable and indicates that device is working which detected on the laptop / pc. Furthermore, the testing successfully to uploaded and compiled program via the Arduino IDE software.

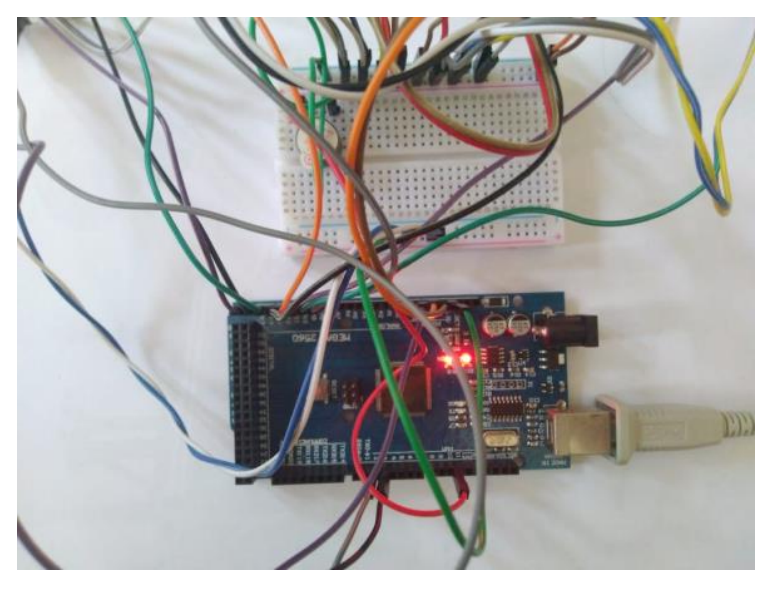

Figure 6. Arduino Mega2560 Testing

\subsubsection{Analog Piezoelectric ceramic vibrate sensor}

Analog piezoelectric sensor, to be used to detect footrests in hopscotch games. The test is carried out with two (2) variations of different foot position tests. The first variation is done by stepping on the puzzle carpet box normally or right in the middle of the carpet, which is right under the puzzle carpet has an analog piezoelectric sensor installed. As shown in Figure 7.a. Testing Foot Position in the middle.
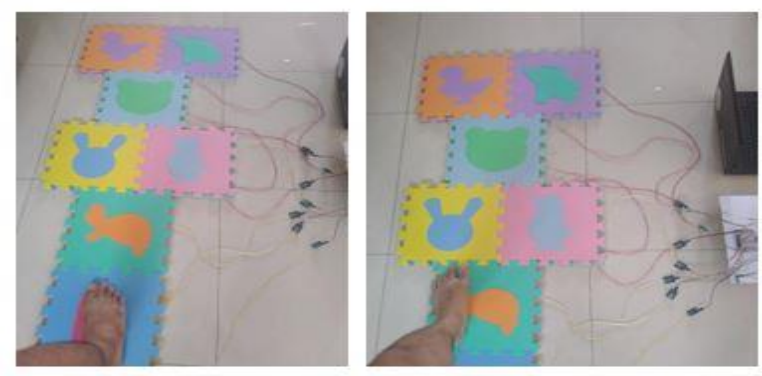

Figure 7.a Test Foot Position in the middle, 7.b in the edge 
then, the second variation of test is done by stepping on 3.2.1. Reading Speed

the puzzle carpet box incorrectly in the middle of carpet, Performance test results on the reading speed can be seen or deviating, such as stepping on the edge of the carpet, in table 3.

shown in Figure 7.b.in the edge.

\subsubsection{Esp8266-01 Wi-Fi Module}

Esp8266-01 is used as a Wi-Fi module to send sensor data to the IoT platform via the internet. On this device, the program uploads data to the internet, done successfully via the Arduino IDE software. Furthermore, the sensor detection results are sent successfully to the IoT platform that is Thingspeak, show below in Figure 8. Sensor Data 1-4 and Figure 9. Sensor Data 5-8.
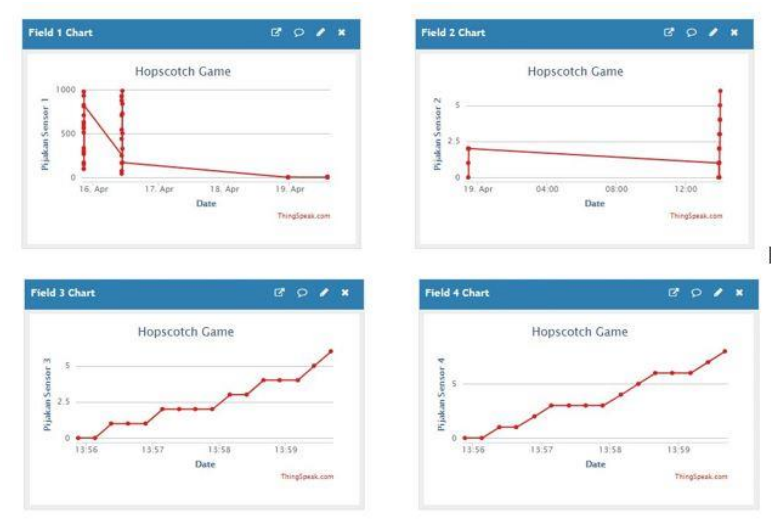

Figure 8. Sensor Data 1-4
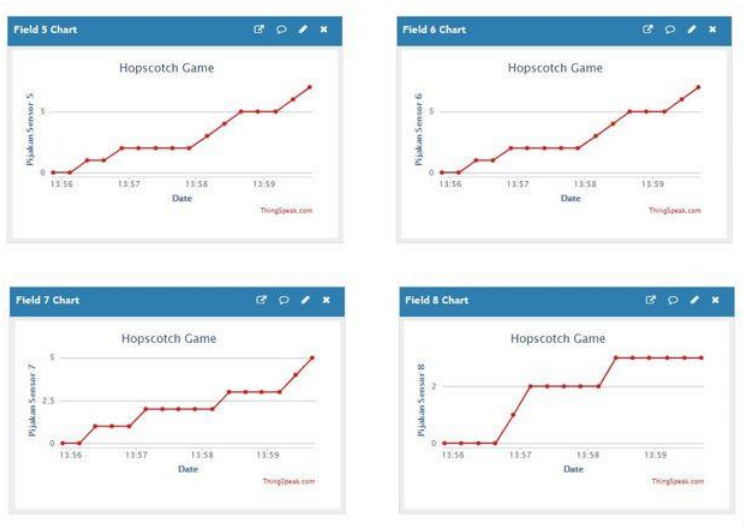

Figure 9. Sensor Data 5-8

Figure 8. Sensor Data 1-4 and Figure 9. Sensor Data 58 , represents how many sensor steps are detected and published to the platform. The graph 1 and 2 in Figure 8 . Sensor Data 1-4, are vertical graph which means that input is constant or static, then the shape of graph will follow according to input. Whereas in figure 9. Sensor data 5-8, graphs 3 until 8 show shape of rising line graph, that input of incoming sensors add continues.

\subsection{System Performance Testing Results}

Testing is done by conducting experiments. One (1) trial test is counted back and forth, or 8 steps +8 steps $=16$ steps.

\begin{tabular}{cccc}
\hline Sensors & No footing & $\begin{array}{c}\text { There is a } \\
\text { foothold }\end{array}$ & $\begin{array}{c}\text { Difference } \\
\text { (Milisecond) }\end{array}$ \\
\hline Sensor 1 & $16: 32: 42: 088$ & $16: 32: 43: 711$ & 1623 \\
Sensor 2 & $16: 35: 21: 412$ & $16: 35: 22: 092$ & 680 \\
Sensor 3 & $16: 36: 14: 583$ & $16: 36: 15: 294$ & 711 \\
Sensor 4 & $16: 37: 12: 548$ & $16: 37: 13: 261$ & 713 \\
Sensor 5 & $16: 39: 04: 706$ & $16: 39: 05: 692$ & 986 \\
Sensor 6 & $16: 40: 08: 982$ & $16: 40: 09: 963$ & 981 \\
Sensor 7 & $16: 41: 08: 080$ & $16: 41: 09: 093$ & 1013 \\
Sensor 8 & $16: 42: 02: 516$ & $16: 42: 03: 535$ & 1019 \\
& Average & & 965.75 \\
\hline
\end{tabular}

Based on result testing on the reading speed parameters, obtained with an average of 965.75 milliseconds (about 0.9 seconds).

From the results testing of the readings carried out by 20-30 times experiments, the reading value is always under 1 second. Readings below 1 -second mean sensor or processing readings become input for less than 1 second, or an overall average under 1 second

\subsubsection{Accuracy of Assessment}

On the accuracy of assessment parameters, technically has been done by requiring setting delay on the program to the system. It necessary, because if the system has not been given by certain delay setting or no delayed in the program, so inaccuracies in system assessment happen, or assessment is not optimal. Likewise, if the specified delay is too large or too small, readings result is too long or too fast, which causes the sensor assessment will incorrectly, so the delay setting must be precised to be optimal.

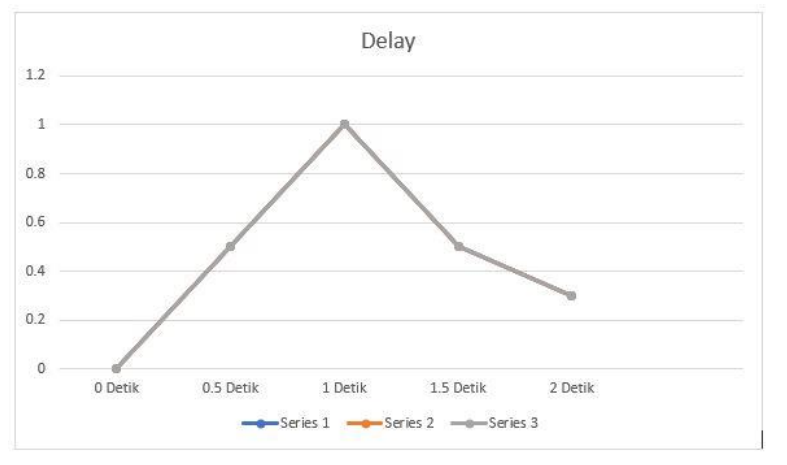

Figure 10. Delay Graph

Figure 10. Delay Graph, showed graph to setting system to run. On the $\mathrm{x}$-axis is the range of program delay times, while the $y$-axis is the percentage of readings. Then the delay setting of 1000 milliseconds (1 second) was chosen because experimentally it obtained the most optimal value at the delay of 1 second. 
The test results on the accuracy of the rate parameters can be seen in table 4 .

Table 4. Accuracy of Assessment

\begin{tabular}{ccc}
\hline Test Variations & Experiments & Trial Averages \\
\hline First & 5 times & $68.75 \%$ \\
Second & 5 times & $81.25 \%$ \\
\hline
\end{tabular}

From the conducted tests results, the average values accuracy of assessment are, in $68.75 \%$ as first test variation and $81.25 \%$ second test variation.

\section{Conclusion}

The analysis and implementation results of the hopscotch game system, by using Internet of Things (IoT) utilization, accurately can be run functionally successes $100 \%$, it means all function in the system can be run as plan. Based on the reading speed parameters, the delay average is less than 1 second, which means that this condition does not affect on the rate accuracy parameter testing. For accuracy of assessment parameters obtained by a maximum program delay setting in 1 second, with value result of this program tested are $68.75 \%$ as first test variation, and $81.25 \%$ as on second test variation.

\section{References}

[1] Agoes Dariyono, Psikologi perkembangan anak usia 3 tahun pertama (psikologi atitama). Refika Aditama, 2007.

[2] "Gross Motor Development Checklist," 2017. [Online]. Available:https://childdevelopment.com.au/resources/childdevelopment-charts/gross-motor-developmental-checklist/.

[3] S. Sunardi, Intervensi Dini Anak Berkebutuhan Khusus. Jakarta: Departemen Pendidikan Nasional Direktorat Jenderal Pendidikan Tinggi Direktorat Ketenagaan, 2007.

[4] Departemen Kesehatan, "Skrining / Pemeriksaan Perkembangan Anak Mneggunakan Kuesioner Pra Skrining Perkembangan (KPSP),"p. 43, 2017.

[5] L. Hestbaek et al., "Influence of motor skills training on children's development evaluated in the Motor skills in PreSchool (MiPS) study-DK: Study protocol for a randomized controlled trial, nested in a cohort study," Trials, vol. 18, no. 1, pp. 1-11, 2017.

[6] Kementerian Pemberdayaan Perempuan dan Perlindungan Anak, "Profil Anak Indonesia Tahun 2019," 2019.

[7] V. Bhuvaneswari and R. Porkodi, "The internet of things (IOT) applications and communication enabling technology standards: An overview," Proc. - 2014 Int. Conf. Intell. Comput. Appl. ICICA 2014, pp. 324-329, 2014.

[8] J. Gómez, J. F. Huete, O. Hoyos, L. Perez, and D. Grigori, "Interaction system based on Internet of things as support for education," Procedia Comput. Sci., vol. 21, pp. 132-139, 2013.

[9] J. Wellings and M. Levine, "The digital promise: Transforming learning with innovative uses of technology," New York Joan Ganz Cooney Cent. Sesame, 2009.

[10] M. Bagheri and S. H. Movahed, "The Effect of the Internet of Things (IoT) on Education Business Model," Proc. - 12th Int. Conf. Signal Image Technol. Internet-Based Syst. SITIS 2016, pp. 435-441, 2017.

[11] I. N. Haris, "Pengaruh Latihan Egrang Dan Gobag Sodor Terhadap Keseimbangan Tubuh Pada Siswa Sdn 1 Subang," J. Chem. Inf. Model., vol. 53, no. 9, pp. 1689-1699, 2019.

[12] D. A. Wiranti and D. A. Mawarti, "Keefektiffan Permainan Engklek Dalam Mengembangkan Kemampuan Motorik Kasar Anak Usia Dini," Refleks. Edukatika J. Ilm. Kependidikan, vol. 9, no. 1, 2018.

[13] N. A. Sriwidari, M. Mustaji, and R. Hasibuan, "The Modification of Hopscotch for Developing Children's Gross Motor and Social," vol. 212, no. Icei, pp. 119-124, 2018.

[14] M. A. Prada, P. Reguera, S. Alonso, A. Morán, J. J. Fuertes, and M. Domínguez, "Communication with resource-constrained devices through MQTT for control education," IFACPapersOnLine, vol. 49, no. 6, pp. 150-155, 2016.

[15] E. B. Hurlock, Developmental psychology. Tata McGraw-Hill Education, 2001.

[16] R. Barrow, H. M dan McGee, A Practical Approach to Measurement in Physical Education. Philadelpia: Lea \& Febiger, 1979.

[17] Kevin Asthon, "That 'Internet of Things ' Thing," RFID J., p. 4986, 2010.

[18] R. F. I. D. Casagras, "the inclusive model for the Internet of Things report," 2011

[19] J. A. Stankovic, "Research directions for the internet of things," IEEE Internet Things J., vol. 1, no. 1, pp. 3-9, 2014.

[20] M. O. Yusuf, "Information and communication technology and education: Analysing the Nigerian national policy for information technology," Int. Educ. J., vol. 6, no. 3, pp. 316321, 2005.

[21] M. A. Bakri, "Studi Awal Implementasi Internet Of Things Pada Bidang Pendidikan," JREC (Journal Electr. Electron., vol. 4, no. 1, pp. 18-23, 2018 .

[22] R. P. Deekshath Dharanya, K. R. Dimpil Kabadia G Deepak Dinakaran, and S. Shanthini Assistant Professor, "IoT Based Environmental Monitoring System using Arduino UNO and Thingspeak," IJSTE-International J. Sci. Technol. Eng. |, vol. 4 , no. 9, pp. 68-75, 2018.

[23] S. Pasha, "Thingspeak Based Sensing and Monitoring System for IoT with Matlab Analysis," Int. J. New Technol. Res., vol. 2, no. 6, pp. 19-23, 2016. 